\title{
Nasal High Flow therapy for neonates: current evidence and future directions
}

\begin{abstract}
Nasal High Flow therapy is a commonly used method of providing non-invasive respiratory support for neonates. It has several potential mechanisms of action: continuous distending pressure, nasopharyngeal dead space washout, provision of heated and humidified gases and reduction of work of breathing. Nasal High Flow is employed in a number of clinical scenarios for preterm and term infants, including primary respiratory and post-extubation support. In recent years, large trials have generated evidence pertinent to these indications. Novel applications for nasal High Flow in neonates warrant further research: during endotracheal intubation, for initial delivery room stabilisation of preterm infants, and in conjunction with minimally invasive surfactant therapy.
\end{abstract}

\section{Key points}

1. The use of nasal High Flow for neonates has increased greatly in recent years.

2. Nasal High Flow may be an effective alternative to CPAP for postextubation support of preterm infants $>28$ weeks' gestation.

3. There is conflicting evidence regarding the use of nasal High Flow for primary respiratory support of preterm infants and practice will depend upon many factors.

\section{Multiple choice questions (one correct answer)}

1. Current evidence supports the efficacy of nasal High Flow (nHF) compared with CPAP for which of the following indications in preterm neonates?
a. Primary respiratory support.
b. Post-extubation support.
c. During intubation.
d. 'Weaning' from CPAP.
e. Delivery room stabilisation.

2. Regarding the use of nHF for neonates:
a. Similar distending pressure is generated irrespective of the infant's weight.
b. nHF interfaces use larger nasal prongs than CPAP.
c. Distending pressure decreases with increasing flow rates.
d. Prongs should be sized to completely occlude the nostrils.
e. nHF may increase nasopharyngeal dead space washout.

3. What advantage does the use of $\mathrm{nHF}$ offer compared with CPAP?
a. $\mathrm{nHF}$ is cheaper.
b. nHF reduces nasal trauma.
c. nHF reduces the risk of chronic lung disease.
d. nHF devices allow clinicians to set a specific distending pressure.
e. nHF does not require heated humidified gas.

\section{Answers}

This is the author manuscript accepted for publication and has undergone full peer review but has not been through the copyediting, typesetting, pagination and proofreading process, which may lead to differences between this version and the Version of Record. Please cite this article as doi: $10.1111 /$ jpc.14374

This article is protected by copyright. All rights reserved. 
1. B. Current meta-analyses indicate that the use of $\mathrm{nHF}$ for post-extubation support of preterm infants results in similar rates of reintubation compared with CPAP. The exception to this is infants $<26$ weeks' gestation, for whom the limited data suggests rates of treatment failure with nHF are high. Studies have shown conflicting results for nHF use as primary respiratory support and 'weaning' from CPAP. The use of nHF during intubation and for delivery room stabilisation requires further investigation.

2. E. Nasopharyngeal dead space washout is a proposed mechanism of action of nHF. Other mechanisms of action include generation of continuous distending pressure, which increases with increasing flow rate and is inversely proportional to infant weight. To avoid excessive distending pressure, nHF prongs (which are smaller than CPAP prongs) should be sized to allow some gas leak around them in the nares.

3. B. Nasal HF reduces rates of nasal trauma compared with CPAP. Current evidence demonstrates no difference in cost between nHF and CPAP when all factors are considered. Nasal HF devices (which all use heated humidified gas) require flow, not pressure, to be set. Current evidence indicates that the rate of chronic lung disease is similar when $\mathrm{nHF}$ is used, compared with CPAP.

\section{Background}

The 1960s saw the advent of endotracheal ventilation support for preterm infants. During this era, mortality rates were high, and complications such as pneumothorax, pulmonary interstitial emphysema and bronchopulmonary dysplasia (BPD) were common. Post-mortem examinations identified hyaline membrane disease (HMD) (1), and subsequently surfactant deficiency was identified as the underlying cause (2). The availability of exogenous surfactant therapy in the 1990s revolutionised neonatal intensive care in Australia, reducing morbidity and mortality $(1,3)$. Despite this, the incidence of BPD remained high, and research turned to non-invasive methods of respiratory support for these infants. Initially, observational studies suggested a reduction in the incidence of BPD when nasal continuous positive airway pressure (CPAP) was used instead of mechanical ventilation $(4,5)$. Randomised studies (6-8) subsequently showed that CPAP could be used from birth, even in extremely preterm infants. Infants managed with CPAP are less likely to receive surfactant, have fewer days of endotracheal ventilation and may have a lower risk of $\operatorname{BPD}(9,10)$. CPAP has now become the mainstay of non-invasive support for preterm infants, although it has some disadvantages: nasal trauma is common (11), the interface is bulky, and highly trained nursing staff are required to manage CPAP. In recent years, an alternative, nasal High Flow (nHF) therapy, has increased greatly in popularity (12). Nasal HF uses smaller binasal prongs and delivers heated, humidified gas at flows of $>1 \mathrm{~L} / \mathrm{min}$, typically $2-8 \mathrm{~L} / \mathrm{min}$ (12). Its widespread use in neonates occurred before evidence for its safety and efficacy was available. Recently, several large trials have evaluated $\mathrm{nHF}$ in various clinical settings. With respect to the clinical applications of nHF, the review will present the available meta-analysis and randomised controlled trial evidence for nHF. Due to the 
relative paucity of evidence regarding mechanisms of action of nHF, these sections have included studies conducted with a variety of research methodologies.

\section{Mechanisms of action Continuous distending pressure}

During CPAP therapy, continuous distending pressure is thought to improve lung mechanics and prevent atelectasis (16). In contrast to CPAP, where the clinician sets the applied distending pressure, nHF requires flow rather than pressure to be selected. Although nHF does generate some distending pressure, this varies with gas flow and leak. Despite initial concerns about excessive pressure generation and risk of pneumothorax $(17,18)$, most in vivo studies have shown that pharyngeal pressure generated by $\mathrm{nHF}$ is a) similar to, or below that generated during CPAP, and b) increases with increased flow rate (13-16). Spence et al. found a linear relationship between flow and intrapharyngeal pressure (15) and Wilkinson et al. found that pharyngeal pressure increased $0.8 \mathrm{~cm} \mathrm{H}_{2} \mathrm{O}$ per $1 \mathrm{~L} /$ min increase in flow (16). Others have demonstrated similar trends but with smaller pressure changes with increasing flow (14).

For a given flow, the delivered pressure appears to be inversely proportional to an infant's weight $(13,16)$ i.e. the smallest infants require less flow to generate the same distending pressure as larger infants. One small study compared pressure generated by two nHF devices Optiflow (Fisher \& Paykel, Auckland, NZ) and Vapotherm (Vapotherm, Exeter, New Hampshire, USA) and showed no pressure differences with flows of 2-6 L/min, and slightly higher pharyngeal pressures with Vapotherm at $8 \mathrm{~L} / \mathrm{min}$ (17). This may reflect the inclusion of a pressure relief valve in the Optiflow system, but not in Vapotherm (17).

Distending pressure is also determined by leak (11); manufacturers recommend a prong size which allows 50\% 'leak' around the nares. Mouth leak also potentially affects pressure generation, although findings from studies investigating this are contradictory $(13,16)$. Distending pressure increases as the leak around the prongs falls; hence appropriate sizing of prongs is an important safety consideration for nHF use.

\section{Nasopharyngeal dead space washout}

Washout of the nasopharyngeal dead space and subsequent carbon dioxide removal has been proposed as a mechanism of action of nHF (18), although no neonatal studies have been performed to confirm this $(19,20)$. A study of neonatal piglets showed that during $\mathrm{nHF}$, carbon dioxide levels reduced in a flow-dependent manner, independent of leak (19). A recent bench-top study with a simulated preterm infant lung model reported faster gas washout during $\mathrm{nHF}$ than during CPAP, over a variety of flow and pressure settings (20), potentially due to more turbulent gas flow during $\mathrm{nHF}$.

This article is protected by copyright. All rights reserved. 
Studies in children with bronchiolitis have shown similar reductions in carbon dioxide levels after nHF commencement $(21,22)$, however, studies in paediatric patients post cardiac surgery have not shown this effect (23).

\begin{abstract}
Heating and humidification of gases
Provision of heated and humidified gas flow is a requirement for all respiratory support modes. Delivery of unheated, unhumidified gas can adversely affect the airway mucosa and mucociliary function, reducing pulmonary compliance and inducing bronchoconstriction $(24,25)$. All commercially available nHF systems therefore deliver heated, humidified gas (21). A laboratory study comparing the temperature and humidity achieved during $\mathrm{nHF}$ and CPAP, using a simulated neonatal lung model, showed that higher mean gas temperatures were achieved during CPAP $\left(34.5^{\circ} \mathrm{C}\right.$ vs. 34.0 ${ }^{\circ} \mathrm{C}, \mathrm{p}<0.01$ ), but higher relative humidity was achieved with nHF (83 vs. $76 \%$, $p<0.01)(26)$. Relative humidity decreased slightly as flow increased during $\mathrm{CPAP}$, whereas it increased with increasing flow during $\mathrm{nHF}(26)$. A neonatal manikin study (27) also reported that overall temperature was higher with CPAP than $\mathrm{nHF}\left(35.5^{\circ} \mathrm{C}\right.$ vs. $\left.34.3^{\circ} \mathrm{C}\right)$, but conversely showed relative humidity fell during $\mathrm{nHF}$ at the highest flow levels. All the devices produced absolute humidity within international recommendations, at flows of $8 \mathrm{~L} / \mathrm{min}$. The clinical significance of minor differences between devices is uncertain.
\end{abstract}

\title{
Reduction of work of breathing
}

The large surface area of the nasopharynx allows humidification and heating of inspired gas, but causes resistance to inspiratory flow (18). CPAP reduces this resistance by splinting the upper airway open (28). Nasal HF delivers gas flows above the peak inspiratory flow of the patient, reducing resistance and work of breathing (WOB) (18). Some studies that have compared the effects of $\mathrm{nHF}$ and CPAP on WOB in neonates have found that both modes reduce respiratory effort (29-31), although de Jongh reported lower indices of WOB with CPAP $5-6 \mathrm{cmH}_{2} \mathrm{O}$ compared with $\mathrm{nHF}$ of 3-5 L/min (32).

\section{Indications for nasal High Flow therapy}

\section{Primary respiratory support}

In 2016, a Cochrane review pooled the available data comparing nHF with CPAP for initial treatment of RDS in preterm infants (4 trials, 439 patients) $(12,33-36)$. With the exception of one small, unpublished study (36), infants were all $>28$ weeks' gestation. One study (35) permitted surfactant treatment using the INSURE technique (intubation-surfactant-extubation) before and after study entry. The review concluded that rates of treatment failure, and need for intubation within seven days, were similar between nHF and CPAP, with no difference in rates of death or BPD.

Since 2016, three further non-inferiority trials have added to the evidence base. While one trial found $\mathrm{nHF}$ to be non-inferior to CPAP, the largest favoured nCPAP and a third, smaller study was inconclusive. Lavizzari et al. found nHF to be non-inferior to CPAP with respect to need for intubation and ventilation in 316 
infants between 29 and 36+6 weeks' gestation (37), with no differences in secondary outcomes. Treatment failure occurred in 10.8 vs. $9.5 \%$ of infants receiving $\mathrm{nHF}$ and CPAP respectively (95\% confidence interval of risk difference, $-6.0 \%, 8.6 \%, p=0.71)$. The multicentre HIPSTER trial conducted by Roberts et al. randomised 564 infants $28-36+6$ weeks' gestation to nHF or CPAP (38). The trial was stopped after $75 \%$ of the planned recruitment due to a significantly higher treatment failure rate (defined by objective oxygenation, blood gas and apnoea criteria) in the nHF group ( $25.5 \%$ vs. $13.3 \%$ in the CPAP group, $p<0.001)$. Intubation rates were similar between groups $(15.5 \%$ nHF vs. $11.5 \%$ CPAP, $p=0.17$ ), including in the $<32$ week GA subgroup. Infants in the nHF group had less nasal trauma $(18.5 \%$ vs. $8.3 \%, p<0.001)$ and less pneumothoraces whilst on allocated treatment $(2.1 \%$ vs. $0.0 \%, p=0.02)$, however median duration of respiratory support was a day longer in the nHF group. A third, smaller, RCT by Shin et al. (39) randomised 85 infants (mean 33 weeks' GA) to nHF or CPAP and was technically inconclusive, although the rate of treatment failure was $38 \%$ in the nHF group vs. $21 \%$ in the CPAP group (95\% confidence interval of risk difference $-1.9 \%, 36.2 \%, p=0.1)$. There were no significant differences in secondary clinical outcomes.

There were important differences in the design of these three studies; the use of surfactant and 'rescue' CPAP in the nHF arms varied. In the Lavizzari trial, infants could receive surfactant before or after trial enrolment, without fulfilling treatment failure criteria, whereas infants in the other trials could not. Almost half of the infants included in Lavizzari's trial received surfactant (nHF: 44\%, CPAP $46 \%$ ). Rates of surfactant administration were similar in both groups; however its use may in part explain the lower rate of treatment failure compared with the other trials, where no infants received surfactant prior to reaching treatment failure criteria. A further difference between the studies is that infants in the Lavizzari study who met failure criteria were intubated and ventilated, whereas those in the nHF arm of the HIPSTER trial were given 'rescue' CPAP. This prevented intubation in $40 \%$ of those who reached treatment failure in the nHF group. Use of 'rescue' CPAP in the nHF group may have influenced secondary outcomes in this trial, and is an important consideration for units instituting nHF without having CPAP available as rescue therapy. Finally, the study by Shin et al. was much smaller and had a much larger non-inferiority margin than the others.

Differences between these studies make a universal recommendation regarding the use of $\mathrm{nHF}$ for primary respiratory support difficult. A 2015 meeting of international experts concluded that while nHF can be considered as an alternative to CPAP, further large RCTs are required to determine its efficacy and safety as primary support for RDS (40). Recently, a panel of international research experts were surveyed to determine consensus guidelines for management of neonates with $\mathrm{nHF}(41)$. There was general support for the use of $\mathrm{nHF}$ as primary therapy for respiratory distress, with consideration of the infant's gestational age and initial oxygen requirement. Individual units may consider these and other factors, such as rate of surfactant use, patient population, and local rate of nasal trauma when choosing between primary support therapies.

This article is protected by copyright. All rights reserved. 
In summary, current evidence for the use of nHF for primary respiratory support of preterm RDS suggests the following:

1. Nasal HF may not be equivalent to CPAP

2. The use of 'rescue' CPAP in the event of nHF failure avoids intubation in many infants

3. There is little evidence to guide primary nHF therapy in infants less than 28 weeks' GA

\section{Post-extubation support}

Most very preterm infants require respiratory support post-extubation. The 2016 Cochrane meta-analysis of nHF post-extubation (6 trials, 934 infants), concluded that there was no difference between nHF and CPAP with respect to treatment failure, reintubation, or secondary outcomes including BPD, in preterm infants $>28$ weeks' gestation (12). Infants randomised to nHF had less nasal trauma and a borderline lower pneumothorax rate. Some studies allowed 'rescue' CPAP prior to reintubation $(33,42-45)$, or crossover from CPAP to nHF in the event of nasal trauma $(42,43)$. The largest study of preterm infants reported that $48 \%$ of infants who reached treatment failure with nHF were successfully treated with 'rescue' CPAP, avoiding reintubation for at least seven days (44).

Two more recent RCTs have similarly found no difference in treatment failure or reintubation rates between nHF and CPAP post-extubation. Kang et al. randomised 161 preterm infants <32 weeks' GA (42) and found no difference in these outcomes overall, but treatment failure was higher with nHF in the smaller infants $\left(26-28^{+6}\right.$ weeks' GA). A second, smaller study found a higher rate of treatment failure, but a similar rate of intubation in infants < 32 weeks' GA managed with $\mathrm{nHF}(46)$; the intubation rates were similar due to the use of rescue CPAP in the $\mathrm{nHF}$ arm.

Similar to the primary support trials, relatively few infants $<28$ weeks' GA have been studied, (233 infants from 2 studies included in the Cochrane metaanalysis). The largest trial that included infants $<28$ weeks' GA reported a much higher treatment failure rate for nHF in infants $<26$ weeks' $G A$, and the authors advised caution in its use as post-extubation support in these infants (44).

Several retrospective cohort studies have demonstrated a longer duration of respiratory support or supplemental oxygen therapy in very preterm infants managed with $\mathrm{nHF}$, compared with $\operatorname{CPAP}(47,48)$. The interpretation of these studies is limited by methodological considerations; there may be significant differences in the severity of lung disease and other comorbidities between the groups. Some RCTs have also shown longer duration of respiratory support with nHF use $(33,38)$, yet others have not $(37,39)$. Importantly, there is no corresponding increase in the incidence of BPD for infants managed with $\mathrm{nHF}$ (12). Further research may inform the best approach to weaning $\mathrm{nHF}$, to minimise the duration of respiratory support for preterm infants.

This article is protected by copyright. All rights reserved. 
In summary:

1. Nasal HF has similar efficacy to CPAP for post-extubation support with respect to reintubation, death and BPD, with the exception of babies $<28$ weeks' gestation, in whom CPAP should be used by preference

2. Following extubation, $\mathrm{nHF}$ is associated with less nasal trauma than CPAP

3. Availability of rescue CPAP may be important for preventing extubation failure when using $\mathrm{nHF}$, and may be preferred as first line therapy in the smallest infants

\section{Weaning from CPAP}

Four RCTs have examined nHF as a strategy for weaning from CPAP, with conflicting effects seen on the duration of supplemental oxygen and respiratory support $(49-52)$. Two studies $(51,52)$ found no difference in outcome, when weaning directly from CPAP was compared with changing to $\mathrm{nHF}$. The third study (49) found that using nHF to wean from CPAP resulted in more days of supplemental oxygen and respiratory support, and a fourth study found the reverse to be true (50). Currently, there is insufficient evidence to guide practice recommendations regarding the use of $\mathrm{nHF}$ for weaning from CPAP.

\section{Use in non-tertiary centres}

Non-tertiary centres have unique considerations when choosing between non-invasive respiratory support modes, such as nursing skills, availability of rescue CPAP, and potential need to transfer deteriorating babies. Thus far, all the evidence for neonatal nHF use comes from tertiary neonatal units. However, a large, multi-centre RCT comparing nHF with CPAP in Australian non-tertiary neonatal units has recently completed recruitment (53) and results are awaited. While cost is a consideration, there is little evidence that nHF is cheaper than CPAP. In the HIPSTER trial, total cost of tertiary hospital stay did not differ significantly between groups (38) and a recent economic evaluation of $\mathrm{nHF}$ found the higher capital equipment costs of CPAP were not outweighed by the higher consumable costs of nHF (54).

\section{Future research directions}

There are a number of potential novel applications for neonatal $\mathrm{nHF}$ therapy that are worthy of evaluation in a research setting:

\section{Intubation support}

Neonatal intubation is a difficult skill to perform; attempts commonly take longer than recommended (55) and result in desaturation or bradycardia (56). A new technique called Transnasal Humidified Rapid-Insufflation Ventilatory Exchange (THRIVE) utilises $\mathrm{nHF}$ to prolong the safe apnoeic time following induction of anaesthesia (57), likely due to upper airway splinting, continuous insufflation, and dead space washout (57). This technique has recently been evaluated in healthy children undergoing anaesthesia (58) and was found to significantly prolong the time to desaturation. No 
studies have investigated this technique in preterm infants who frequently become unstable during intubation.

\section{Nasal High Flow for delivery room stabilisation of preterm infants}

Nasal HF may be of value as a method of stabilisation for preterm infants in the delivery room. It is quick and easy to apply and it is postulated that it may stimulate respiration and improve gas exchange (59), avoiding the need for immediate CPAP or PPV Nasal HF use in the delivery room has only been reported in a single, small, observational study of infants $<30$ weeks' GA (59); most infants were successfully stabilised with $\mathrm{nHF}$ and overall intubation rates were lower than the unit average prior to the study. The use of delivery room nHF has yet to be evaluated in adequately powered randomised trials.

\section{Nasal High Flow during neonatal transport}

The use of nHF in elective and emergency neonatal transport has been reported (60) in one UK study of 102 infants. Whilst no comparison was made with transports on CPAP, the authors reported a very small $(2 \%)$ increase in oxygen requirement during transport on $\mathrm{nHF}$ and it was felt to be safe and effective. Provision of 'rescue' CPAP during transport in the event of patient deterioration may present a logistic challenge, therefore this requires further exploration before widespread implementation.

Other avenues for future research into nHF use in preterm infants include:

- Comparisons between commercially-available nHF devices

- Investigating the best approach to weaning $\mathrm{nHF}$, particularly given concerns about duration of supplemental oxygen and respiratory support

- Further evaluation of nHF use in extremely preterm infants

\section{Conclusions}

Nasal HF therapy is a relatively new addition to the neonatal intensive care environment. There is good evidence for its use as an alternative to CPAP for postextubation respiratory support; however, CPAP should be available as 'rescue' therapy in the event of nHF failure. Caution should also be applied in using nHF in extremely preterm infants. Evidence for primary respiratory support and weaning from CPAP is less clear-cut. As nHF use in tertiary and non-tertiary centres increases, further research is required regarding specific aspects of the therapy, and to explore new therapeutic indications.

This article is protected by copyright. All rights reserved. 


\section{References}

1. Fujiwara T, Maeta $\mathrm{H}$, Chida S, Morita T, Watabe $\mathrm{Y}, \mathrm{Abe} \mathrm{T}$. Artificial surfactant therapy in hyaline-membrane disease. Lancet (London, England). 1980;1(8159):55-9. 2. Avery ME, Mead J. Surface properties in relation to atelectasis and hyaline membrane disease. AMA journal of diseases of children. 1959;97(5, Part 1):517-23. 3. Merritt TA, Hallman M, Bloom BT, Berry C, Benirschke K, Sahn D, et al. Prophylactic treatment of very premature infants with human surfactant. $\mathrm{N}$ Engl J Med. 1986;315(13):785-90.

4. Avery ME, Tooley WH, Keller JB, Hurd SS, Bryan MH, Cotton RB, et al. Is chronic lung disease in low birth weight infants preventable? A survey of eight centers. Pediatrics. 1987;79(1):26-30.

5. Van Marter $\amalg$, Allred EN, Pagano M, Sanocka U, Parad R, Moore M, et al. Do clinical markers of barotrauma and oxygen toxicity explain interhospital variation in rates of chronic lung disease? The Neonatology Committee for the Developmental Network. Pediatrics. 2000;105(6):1194-201.

6. Dunn MS, Kaempf J, de Klerk A, de Klerk R, Reilly M, Howard D, et al. Randomized trial comparing 3 approaches to the initial respiratory management of preterm neonates. Pediatrics. 2011;128(5):e1069-76.

7. Finer NN, Carlo WA, Walsh MC, Rich W, Gantz MG, Laptook AR, et al. Early CPAP versus surfactant in extremely preterm infants. NEJM. 2010;362(21):1970-9. 8. Morley CJ, Davis PG, Doyle LW, Brion LP, Hascoet JM, Carlin JB. Nasal CPAP or intubation at birth for very preterm infants. NEJM. 2008;358(7):700-8.

9. Fischer HS, Buhrer C. Avoiding endotracheal ventilation to prevent bronchopulmonary dysplasia: a meta-analysis. Pediatrics. 2013;132(5):e1351-60. 10. Schmolzer GM, Kumar M, Pichler G, Aziz K, O'Reilly M, Cheung PY. Noninvasive versus invasive respiratory support in preterm infants at birth: systematic review and meta-analysis. BMJ (Clinical research ed). 2013;347.

11. Imbulana DI, Manley BJ, Dawson JA, Davis PG, Owen LS. Nasal injury in preterm infants receiving non-invasive respiratory support: a systematic review. Arch Dis Child Fetal Neonatal Ed. 2018;103(1):F29-F35.

12. Wilkinson D, Andersen C, O'Donnell CP, De Paoli AG, Manley BJ. High flow nasal cannula for respiratory support in preterm infants. Cochrane Database Syst Rev. 2016;2:CD006405.

13. Kubicka ZJ, Limauro J, Darnall RA. Heated, humidified high-flow nasal cannula therapy: yet another way to deliver continuous positive airway pressure? Pediatrics. 2008;121(1):82-8.

14. Lampland AL, Plumm B, Meyers PA, Worwa CT, Mammel MC. Observational study of humidified high-flow nasal cannula compared with nasal continuous positive airway pressure. J Pediatr. 2009;154(2):177-82.

15. Spence KL, Murphy D, Kilian C, McGonigle R, Kilani RA. High-flow nasal cannula as a device to provide continuous positive airway pressure in infants. Journal

This article is protected by copyright. All rights reserved. 
of perinatology : official journal of the California Perinatal Association. 2007;27(12):772-5.

16. Wilkinson DJ, Andersen CC, Smith K, Holberton J. Pharyngeal pressure with high-flow nasal cannulae in premature infants. Journal of perinatology : official journal of the California Perinatal Association. 2008;28(1):42-7.

17. Collins CL, Holberton JR, Konig K. Comparison of the pharyngeal pressure provided by two heated, humidified high-flow nasal cannulae devices in premature infants. Journal of paediatrics and child health. 2013;49(7):554-6.

18. Dysart K, Miller TL, Wolfson MR, Shaffer TH. Research in high flow therapy: mechanisms of action. Respiratory medicine. 2009;103(10):1400-5.

19. Frizzola M, Miller TL, Rodriguez ME, Zhu Y, Rojas J, Hesek A, et al. High-flow nasal cannula: impact on oxygenation and ventilation in an acute lung injury model. Pediatric pulmonology. 2011;46(1):67-74.

20. Sivieri EM, Foglia EE, Abbasi S. Carbon dioxide washout during high flow nasal cannula versus nasal CPAP support: An in vitro study. Pediatric pulmonology. 2017.

21. Bressan S, Balzani M, Krauss B, Pettenazzo A, Zanconato S, Baraldi E. Highflow nasal cannula oxygen for bronchiolitis in a pediatric ward: a pilot study. European journal of pediatrics. 2013;172(12):1649-56.

22. Kallappa C, Hufton M, Millen G, Ninan TK. Use of high flow nasal cannula oxygen (HFNCO) in infants with bronchiolitis on a paediatric ward: a 3-year experience. Archives of disease in childhood. 2014;99(8):790-1.

23. Testa G, lodice F, Ricci Z, Vitale V, De Razza F, Haiberger R, et al. Comparative evaluation of high-flow nasal cannula and conventional oxygen therapy in paediatric cardiac surgical patients: a randomized controlled trial. Interactive cardiovascular and thoracic surgery. 2014;19(3):456-61.

24. Fontanari $\mathrm{P}$, Burnet $\mathrm{H}$, Zattara-Hartmann $\mathrm{MC}$, Jammes $\mathrm{Y}$. Changes in airway resistance induced by nasal inhalation of cold dry, dry, or moist air in normal individuals. Journal of applied physiology (Bethesda, Md : 1985). 1996;81(4):1739-

43.

25. Sottiaux TM. Consequences of under- and over-humidification. Respiratory care clinics of North America. 2006;12(2):233-52.

26. Chang GY, Cox CA, Shaffer TH. Nasal cannula, CPAP, and high-flow nasal cannula: effect of flow on temperature, humidity, pressure, and resistance.

Biomedical instrumentation \& technology. 2011;45(1):69-74.

27. Roberts CT, Kortekaas R, Dawson JA, Manley BJ, Owen LS, Davis PG. The effects of non-invasive respiratory support on oropharyngeal temperature and humidity: a neonatal manikin study. Arch Dis Child Fetal Neonatal Ed.

2016;101(3):F248-52.

28. Chowdhury O, Wedderburn CJ, Duffy D, Greenough A. CPAP review. European journal of pediatrics. 2012;171(10):1441-8.

This article is protected by copyright. All rights reserved. 
29. Saslow JG, Aghai ZH, Nakhla TA, Hart JJ, Lawrysh R, Stahl GE, et al. Work of breathing using high-flow nasal cannula in preterm infants. Journal of perinatology : official journal of the California Perinatal Association. 2006;26(8):476-80.

30. Shetty S, Hickey A, Rafferty GF, Peacock JL, Greenough A. Work of breathing during CPAP and heated humidified high-flow nasal cannula. Arch Dis Child Fetal Neonatal Ed. 2016;101(5):F404-7.

31. Lavizzari A, Veneroni C, Colnaghi M, Ciuffini F, Zannin E, Fumagalli M, et al. Respiratory mechanics during NCPAP and HHHFNC at equal distending pressures. Arch Dis Child Fetal Neonatal Ed. 2014;99(4):F315-20.

32. de Jongh BE, Locke R, Mackley A, Emberger J, Bostick D, Stefano J, et al. Work of breathing indices in infants with respiratory insufficiency receiving high-flow nasal cannula and nasal continuous positive airway pressure. Journal of perinatology : official journal of the California Perinatal Association. 2014;34(1):27-32.

33. Yoder BA, Stoddard RA, Li M, King J, Dirnberger DR, Abbasi S. Heated, humidified high-flow nasal cannula versus nasal CPAP for respiratory support in neonates. Pediatrics. 2013;131(5):e1482-90.

34. Ciuffini F, Pietrasanta C, Lavizzari A, Musumeci S, Gualdi C, Sortino S, et al. Comparison between two different modes of non-invasive ventilatory support in preterm newborn infants with respiratory distress syndrome mild to moderate: preliminary data. La Pediatria medica e chirurgica : Medical and surgical pediatrics. 2014;36(4):88.

35. Iranpour. High-flow nasal cannula versus nasal continuous positive airway pressure in the management of respiratory distress syndrome. Published and unpublished data. Journal of Isfahan Medical School. 2011;2011;29(143):1.

36. Nair G KP. Comparison of the effects of Vapotherm and nasal CPAP in respiratory distress. . Pediatric Academic Societies, Unpublished data. 2005.

37. Lavizzari A, Colnaghi M, Ciuffini F, Veneroni C, Musumeci S, Cortinovis I, et al. Heated, Humidified High-Flow Nasal Cannula vs Nasal Continuous Positive Airway Pressure for Respiratory Distress Syndrome of Prematurity: A Randomized Clinical Noninferiority Trial. JAMA pediatrics. 2016.

38. Roberts CT, Owen LS, Manley BJ, Froisland DH, Donath SM, Dalziel KM, et al. Nasal High-Flow Therapy for Primary Respiratory Support in Preterm Infants. N Engl J Med. 2016;375(12):1142-51.

39. Shin J, Park K, Lee EH, Choi BM. Humidified High Flow Nasal Cannula versus CPAP as Initial Respiratory Support in Preterm Infants. Journal of Korean medical science. 2017;32(4):650-5.

40. Roehr CC, Yoder BA, Davis PG, Ives K. Evidence Support and Guidelines for Using Heated, Humidified, High-Flow Nasal Cannulae in Neonatology: Oxford Nasal High-Flow Therapy Meeting, 2015. Clin Perinatol. 2016;43(4):693-705.

This article is protected by copyright. All rights reserved. 
41. Yoder BA, Manley B, Collins C, Ives K, Kugelman A, Lavizzari A, et al.

Consensus approach to nasal high-flow therapy in neonates. Journal of perinatology: official journal of the California Perinatal Association. 2017.

42. Kang WQ, Xu BL, Liu DP, Zhang YD, Guo J, Li ZH, et al. [Efficacy of heated humidified high-flow nasal cannula in preterm infants aged less than 32 weeks after ventilator weaning]. 2016;18(6):488-91.

43. Collins CL, Holberton JR, Barfield C, Davis PG. A randomized controlled trial to compare heated humidified high-flow nasal cannulae with nasal continuous positive airway pressure postextubation in premature infants. J Pediatr. 2013;162(5):949-54 e1.

44. Manley BJ, Owen LS, Doyle LW, Andersen CC, Cartwright DW, Pritchard MA, et al. High-flow nasal cannulae in very preterm infants after extubation. NEJM. 2013;369(15):1425-33.

45. Mostafa-Gharehbaghi M, Mojabi H. Comparing the Effectiveness of Nasal Continuous Positive Airway Pressure (NCPAP) and High Flow Nasal Cannula (HFNC) in Prevention of Post Extubation Assisted Ventilation. Zahedan Journal of Research in Medical Sciences. 2015;17(6).

46. Soonsawad S, Swatesutipun B, Limrungsikul A, Nuntnarumit P. Heated Humidified High-Flow Nasal Cannula for Prevention of Extubation Failure in Preterm Infants. Indian journal of pediatrics. 2017;84(4):262-6.

47. Hoffman SB, Terrell N, Driscoll CH, Davis NL. Impact of High-Flow Nasal Cannula Use on Neonatal Respiratory Support Patterns and Length of Stay. Respiratory care. 2016;61(10):1299-304.

48. Taha DK, Kornhauser M, Greenspan JS, Dysart KC, Aghai ZH. High Flow Nasal Cannula Use Is Associated with Increased Morbidity and Length of Hospitalization in Extremely Low Birth Weight Infants. J Pediatr. 2016;173:50-5 e1.

49. Abdel-Hady H, Shouman B, Aly H. Early weaning from CPAP to high flow nasal cannula in preterm infants is associated with prolonged oxygen requirement. Early human development. 2011;87(3):205-8.

50. Badiee Z, Eshghi A, Mohammadizadeh M. High flow nasal cannula as a method for rapid weaning from nasal continuous positive airway pressure. International journal of preventive medicine. 2015;6:33.

51. Tang J, Reid S, Lutz T, Malcolm G, Oliver S, Osborn DA. Randomised controlled trial of weaning strategies for preterm infants on nasal continuous positive airway pressure. BMC Pediatr. 2015;15:147.

52. Soonsawad S, Tongsawang N, Nuntnarumit P. Heated Humidified High-Flow Nasal Cannula for Weaning from Continuous Positive Airway Pressure in Preterm Infants: A Randomized Controlled Trial. Neonatology. 2016;110(3):204-9.

53. Manley BJ, Roberts CT, Arnolda GRB, Wright IMR, Owen LS, Dalziel KM, et al. A multicentre, randomised controlled, non-inferiority trial, comparing nasal high flow with nasal continuous positive airway pressure as primary support for newborn

This article is protected by copyright. All rights reserved. 
infants with early respiratory distress born in Australian non-tertiary special care nurseries (the HUNTER trial): study protocol. BMJ Open. 2017;7(6):e016746.

54. Fleeman N, Mahon J, Bates V, Dickson R, Dundar Y, Dwan K, et al. The clinical effectiveness and cost-effectiveness of heated humidified high-flow nasal cannula compared with usual care for preterm infants. Health technology assessment (Winchester, England). 2016;20(30):1-68.

55. O'Donnell CP, Kamlin CO, Davis PG, Morley CJ. Endotracheal intubation attempts during neonatal resuscitation: success rates, duration, and adverse effects. Pediatrics. 2006;117(1):e16-21.

56. Hatch LD, Grubb PH, Lea AS, Walsh WF, Markham MH, Whitney GM, et al. Endotracheal Intubation in Neonates: A Prospective Study of Adverse Safety Events in 162 Infants. J Pediatr. 2016;168:62-6 e6.

57. Patel A, Nouraei SA. Transnasal Humidified Rapid-Insufflation Ventilatory Exchange (THRIVE): a physiological method of increasing apnoea time in patients with difficult airways. Anaesthesia. 2015;70(3):323-9.

58. Humphreys S, Lee-Archer P, Reyne G, Long D, Williams T, Schibler A. Transnasal humidified rapid-insufflation ventilatory exchange (THRIVE) in children: a randomized controlled trial. British journal of anaesthesia. 2017;118(2):232-8.

59. Reynolds P, Leontiadi S, Lawson T, Otunla T, Ejiwumi O, Holland N.

Stabilisation of premature infants in the delivery room with nasal high flow. Arch Dis Child Fetal Neonatal Ed. 2016;101(4):F284-7.

60. Boyle MA, Dhar A, Chaudhary R, Kent S, O'Hare SS, Dassios T, et al. Introducing high-flow nasal cannula to the neonatal transport environment. Acta Paediatr. 2017;106(3):509-12.

This article is protected by copyright. All rights reserved. 
(i) Nasal High Flow therapy for neonates: current evidence and future directions

(ii) Review article

(iii) Dr Kate A Hodgson

Prof Peter G Davis

Dr Louise S Owen

(iv) Newborn Research Centre

Royal Women's Hospital

20 Flemington $\mathrm{Rd}$

Parkville VIC 3052

(v) Newborn Research Centre

Royal Women's Hospital

20 Flemington $\mathrm{Rd}$

Parkville VIC 3052

Kate.Hodgson@thewomens.org.au

+61383453763

This article is protected by copyright. All rights reserved. 


\section{University Library}

\section{- M M I N E R VA A gateway to Melbourne's research publications}

Minerva Access is the Institutional Repository of The University of Melbourne

Author/s:

Hodgson, KA;Davis, PG;Owen, LS

Title:

Nasal high flow therapy for neonates: Current evidence and future directions

Date:

2019-03-01

Citation:

Hodgson, K. A., Davis, P. G. \& Owen, L. S. (2019). Nasal high flow therapy for neonates:

Current evidence and future directions. JOURNAL OF PAEDIATRICS AND CHILD HEALTH, 55 (3), pp.285-290. https://doi.org/10.1111/jpc.14374.

Persistent Link:

http://hdl.handle.net/11343/285258 